\title{
Book Review: Instructional Design Theories and Models -A New Paradigm of Instructional Theory-
}

\author{
Hasan Caliskan \\ Anadolu University, Turkey
}

\section{Introduction}

Instructional Design Theories and Models: A New Paradigm of Instructional Design Theory (Volume II) is edited by Charles M. Reigeluth of Indiana University (USA) and published by Lawrence Erlbaum Associates (located in Mahwah, New Jersey) in 1999 with an ISBN 0-80582859-1. The book is totally 715 pages.

This book is organized into five units. The first two introductory units provide a framework for understanding the following three units that provide a deep understanding going into details of a variety of instructional theories and models. Following three units present instructional design theories in respect to the cognitive, psychomotor, and affective development areas. Various topics all along the book stay focused to the idea of systems approach to learning.

The book describes a number of instructional theories and models providing details on when and how to use each. Stated differently, it tries to enlighten the path that leads to the answer of question "how to help people learn better." The book provides a collection of sound information on the instructional design theory both for practitioners and researchers underlying well known as well as under-development theories/approaches in the field. It also shows the interrelationships among these diverse theories and highlights current issues along with trends in instructional design field.

\section{The Editor}

The editor, Charles M. Reigeluth, has been a professor of instructional systems technology at Indiana University since 1988. His research interests mainly include redesigning educational systems and designing high quality learning resources. Reigeluth's publications include eight books of which the two have received "Outstanding Book of the Year Awards" from the Association for Educational Communications and Technology (AECT).

\section{Why This Book?}

Instructional theory is about "how to help people learn better without loosing the focus of how people learn." Any theory, thus, tries to describe the variety of ways for facilitating learning as well as describing how and when to use some effective methods for learning. Volume I of the Instructional Design Theories and Models: An Overview of Their Current 
Status, which was published in 1983, provided a general description and explanation of the theory and as well as its status in the early 1980s.

The nature of instructional theory has changed in nature in response to a variety of different needs in educational and training settings by the time. As a result of such changes, people in the field have started to discuss a need for a new paradigm of instructional theory explaining and fulfilling such changes and needs.

\section{The Units at a Glance}

The first unit introduces two introductory papers presenting perspectives on the theories and changes that have occurred since the first volume. The unit describes instructional design theory and the ways it is changing as well as the reasons for this change. It also discusses current issues and trends in the field. At the beginning of the unit, Reigeluth defines the design and theory terminology. He provides a basis for readers so that they can analyze and understand the instructional design theories given in the rest of the book. The author strongly recommends that readers should read the two chapters in this unit before they go any further in the book especially in the theories. Another author providing contribution in this unit besides Reigeluth is Snelbecker.

The following three units that form the core of the book contain twenty-three papers presented by thirty-eight authors. These papers mainly deal with descriptions and discussions on the state of learning and instructional design theory. Unit 2 gives a useful and short summary of the new instructional design theories under the cognitive domain as well as the methods and explanations when to use them. Unit 3 provides the same information for one particular theory that integrates a wide variety of methods from a variety of theoretical perspectives in the psychomotor domain. Unit 4 does the same for five theories in the affective domain.

In each of the units, Reigeluth organizes the content in such a manner that readers have a chance to get the idea and big picture for the rest of the unit. Reigeluth does this by explaining the selected content and his thoughts about the subject matter briefly introducing each unit.

Reigeluth also does the same thing for each of the papers included in the three units that discuss the instructional design theories. He provides at the beginning of each paper a brief idea of what the content is all about and how the readers will be able to use the knowledge in them during their teaching. To do this, Reigeluth uses a framework in each paper to introduce the discussed theory or idea. This is kind of a summary for the rest of the content but it is especially important and useful for those who might feel novice in the field or sometimes lost in the whole book as for what to do with the content. Then the content gives the details in a deeper manner on the subject matter. In each of the paper, Reigeluth uses the following format:

Goals and preconditions

Values

Methods and

Major contributions 
Authors of the papers included in these three units are recognized authorities on the included topics such as Reigeluth, Jonassen, Hanaffin, Gardner, Ramiszowski, Merrill, Moore, Landa, Mayer, Collins, Lewis, Watson, Perkins, McCormick, Kamradt, Unger, Land, Oliver, Schank, Berman, Macpherson, Schwartz, Lin, Brophy, Bransford, Nelson, Bielaczyc, Corno, Randi, Pogrow, Kovalik, McGeehan, Martin, Schaps, Stone-McCown, Kamradt, Lickona, and Moore. Majority of these authors have been contributing to the field for quite a long time on many issues with exemplary works of which many are seen as milestones.

The last unit (5) provides a general discussion of the various theories presented in the previous three (2-4) and a research methodology to provide a basis for developing the knowledge base about this new introduced paradigm of instruction. Contributors of this last unit are Reigeluth himself, Firck, and Snelbecker.

\section{A Closer Look at the Units: The Chapters}

\section{Unit 1 (Chapters 1-2)}

This unit has two chapters that aim to help the reader analyze and understand the followings:

- The nature of the theories in the book

- The ways this new paradigm of instructional design theory differs from the previous paradigm

- Some issues about instructional design theories that are of interest to both researchers and practitioners

In this volume, Reigeluth uses the term "design theory" in place of "prescriptive theory" which was used in Volume I as the alternative to descriptive theory. The reason for the change is for the rigidity and inflexibility of the concept of "prescription". He also warns the readers that he uses the term instructional theory with the same meaning as instructional design theory for the sake of brevity.

This unit introduces many of the issues that are addressed throughout the book. The following issues are raised in the unit in coherence with the structure of the whole book:

- key characteristics of the new paradigm of instruction

- instructional theory and the ways it differs from learning theory and instructional systems development (ISD) processes

- roles of values about instruction in the design of instruction

- the extent of the integration of instructional theory and curriculum theory

- the extent instruction addresses cognitive, psychomotor, and affective domains

- the extent diversity of methods is offered to practitioners

- the extent of flexibility that an instructional theory offers to practitioners

- the extent of details an instructional theory offers to practitioners for guidance

- the extent culture or climate of the learning environment should be a method in an instructional theory

- the role of methods of motivating students in the new paradigm of instruction

- the role of student self-regulation and reflection on learning in the new paradigm of instruction

- the nature of student assessment for the new paradigm of instruction 
- systemic thinking and the extent it is important to designing and implementing a new paradigm of instruction

- "either-or" thinking in the new paradigm of instructional theory

- additional kinds of learning the new paradigm of instructional theory deals with

- the roles of teachers and students in the new paradigm of instruction and the implications of those new roles for professional development of teachers

Reigeluth underlines two important themes in this volume. One of them is that cognitive, affective, and behavioral (psychomotor) developments are strongly linked together. On the other hand, ways of fostering cognitive development will be different than the ways that of affective. Thus, it is important for Reigeluth to understand both the differences and the interrelatedness of these domains of human learning and development.

The second important theme is about the interrelatedness of curriculum theory and instructional theory. Instructional theory, learning theory, and the ISD process (development theory) are interrelated. The different domains of learning are interrelated, and within each of these domains, the different subject areas are interrelated. Reigeluth suggests that the systems thinking and chaos theory provide powerful tools for identifying and understanding the interrelationships. A well study of these areas is likely to affect practitioners' ability to successfully implement the new paradigm of instructional theory as well as theorists' ability to successfully build a sound instructional theory.

\section{Unit 2 (Chapters 3-18)}

Reigeluth starts with chapter 3 in this unit to provide the reader with help for analyzing and understanding the theories included in the twenty-three papers. This chapter goes into details about instructional-design theories providing important dimensions and differences among them as well as types of learning these theories each of the theories addresses. This framework is useful for better understanding the interrelations among all.

At this point Reigeluth shares his thoughts with the readers about the content organization of the book and the unit in particular. He admits that it was not an easy job to decide which theories to include in this unit since there have been a lot of interesting and exciting advancements on this new paradigm in the cognitive domain. He also regrets that he was not able to include certain works or contributions in this unit. To give examples of such works, he mentions Anderson and Spiro's works. He also regrets the limitation of contributions in terms of geography for there are no papers in this volume outside the North America.

After sharing these limitations and regrets with the reader, Reigeluth promises the next volume to his readers and his intention to immediately start working on the Volume III. Indeed, this particular volume has just been published by Tylor \& Francis group in 2009 under the theme "Building a Common Knowledge Base." Carr-Chellman in this volume is the co-editor of Reigeluth.

Reigeluth arranged the theories in this unit according to their main similarities. After the opening and introductory chapter 3 , he continues with chapter 4 to 7 which are mainly on understanding. Ways of fostering understanding is underlined. Problem-based learning is the main focus of chapters 8 to 11 . Chapters 11 to 13 emphasize the importance of collaboration and self-regulation in learning process. Chapters 14 and 15 primarily focus on 
higher-order thinking skills. Chapters 16 to 18 , on the other hand, deal with a variety of other concerns addressing most of the categories to some extent.

Reigeluth warns the readers at this point that any of these theories are not superior to each other. They fulfill the gaps or less touched parts of each other. Readers at this point can make use of the chapter forewords and editor's notes to better understand the relations among them.

\section{Unit 3 (Chapter 19)}

Only one theory is discussed in Unit 3. The chapter introduces the psychomotor domain. Development of physical skills and the ways of fostering psychomotor development is the main idea of the unit. Although there is only one theory in the unit, Reigeluth underlines the fact that it integrates a wide variety of methods from a variety of theoretical perspectives. He encourages readers to explore methods and principles or guidelines offered for psychomotor domain. He also invites readers to compare similarities and differences of the use of these methods or/and guidelines between psychomotor and cognitive domains.

\section{Unit 4 (Chapters 20-25)}

Reigeluth starts the unit with Chapter 20 giving readers a chance to analyze and understand the theories available in the unit. This chapter provides a conceptual model that shows the six main dimensions of affective development. It also presents major components that have instructional value for each of the dimensions. Chapter 20 also provides an application model that shows eight of the more important dimensions. Therefore, readers will better understand how instructional-design theories can differ from each other in the affective domain.

Theory chapters in this unit start with Chapter 21. This chapter provides a bridge between cognitive and affective domains. The following chapters, then, continue with the other dimensions of the domain. Chapter 22 focuses on emotional development while Chapter 23 does on attitudes development. Chapter 24 focuses on the character education underlining the cultivation of virtue. The last chapter of the unit (25) deals mainly with the spiritual development explaining the stages and strategies. Since these five theories do not examine the affective development in a deep manner. For this reason, readers will be in need of extra guidance as they read through the theories in this unit. Reigeluth admits that these five chapters only begin to scratch the surface of the work that has been initiated by theorists all over the world related to affective development.

It is the editor's hope that the inclusion of these five chapters will increase awareness on the affective dimensions of human learning and development as they get into the instructional design theory either as practitioners or researchers.

\section{Unit 5 (Chapters 26-27)}

The first chapter in this unit (26) deals with the description of an action or developmental research process/method that best suits the developing design theory. Reigeluth, at this point, hopes that the information provided in this chapter will raise awareness for both the 
need and the development of some additional methodologies for the design theory. The last chapter of the unit (27) provides reflections on the overall theories included in this particular volume. Reigeluth thinks that this chapter will help readers see the big picture providing a broader perspective of the theories.

\section{Closure: Post Script}

In the closure of the Volume II, Reigeluth shares his thoughts with readers. He repeats that he has already started working on the Volume III as he has worked on the new paradigm for the current volume. He wants to encourage the readers to provide and share any useful information or idea for this new volume. As mentioned above, Volume III has already been published.

He concludes the book with the belief that he has done a useful work to provide guidance for the design of approaches to learning and human development that both are learning focused. He also believes that there are still a lot of works to be done to help and guide teachers, trainers, software designers, textbook authors, and many other professionals dealing with fostering human learning and development.

It is the editor's hope that this particular Volume /I will help more people decide working in this field, help practitioners and researchers publish more journals as well as papers in the field, help more funders support works in this area, help more policy makers implement work of this kind to serve the field in a deep manner. The editor concludes his remarks stating the importance of development of electronic performance support systems in order for practitioners to select and apply the best suitable and appropriate design theories for their specific goals, conditions, and values.

\section{Final Remarks}

This book is a collection of detailed summaries of all the important work in the field with extensive references to further readings and practices. Reigeluth makes it clear that professionals in the field should spend more time for working on finding solutions to the instructional problems because the field needs working methods and processes for rapid change and growth.

As a well-known figure in the field, Reigeluth has gathered many of the best minds in instructional theory and collected their significant works into this book. He allows various authors to present a variety of different instructional theories and approaches, provides valuable frameworks for them, and summarizes all topics included in the book. Without standing by one particular theory or approach over others, the editor of the book puts forward each theory/model with its pros and cons so that each is given a chance to offer its examples of process and results in its own limits.

If you are looking for a clear picture of the profession of instructional design along with the human learning and development as of 1999, then you might want to take a look at this volume. Practitioners of the profession, researchers in the field, corporate trainers focused on performance, graduate students who want to see the overall picture of the field, and in fact anyone who is interested in learning and human development at any level should read this book thoroughly. This book has been a reference called "bible" for many people in the 
field of instructional design and development. It is also essential that readers "must" have a grasp of this volume to get the most from the third volume.

Correspondence: Hasan Caliskan, Assistant Professor, Faculty of Communication Sciences, Anadolu University, Yunus Emre Campus, Eskisehir 26470, Turkey 